\title{
Groundwater Flow Modeling in the KURT site for a Case Study about a Hypothetical Geological Disposal Facility of Radioactive Wastes
}

\section{방사성폐기물 지하처분장에 대한 가상의 사례 연구를 위한 KURT 부지의 지하수 유동 모의}

\author{
Nak-Youl Ko1), Kyung Woo Park, Kyung Su Kim and Jong Won Choi \\ Korea Atomic Energy Research Institute, 989-111 Daedeok-Daero, Yuseong-Gu, Daejeon \\ 고낙열1), 박경우, 김경수, 최종원 \\ 한국원자력연구원, 대전시 유성구 대덕대로 989 번길 111
}

(Received August 10, 2012 / Revised September 13, 2012 / Approved September 14, 2012)

\begin{abstract}
Groundwater flow simulations were performed to obtain data of groundwater flow used in a safety assessment for a hypothetical geological disposal facility assumed to be located in the KURT (KAERI Underground Research Tunnel) site. A regional scale modeling of the groundwater flow system was carried out to make boundary conditions for a local scale modeling. And, fracture zones identified at the study site were involved in the local scale groundwater flow model. From the results of the local scale modeling, a hydraulic head distribution was indicated and it was used in a particle tracking simulation for searching pathway of groundwater from the location of the hypothetical disposal facility to the surface where the groundwater reached. The flow distance and discharge rate of the groundwater in the KURT site were calculated. It was thought that the modeling methods used in this study was available to prepare the data of groundwater flow in a safety assessment for a geological disposal facility of radioactive wastes.
\end{abstract}

Key words : Groundwater flow modeling, Hydrogeological model, Particle tracking simulation, Groundwater pathway

\section{요 약}

한국원자력연구원의 지하처분연구시설인 KURT 부지에 가상의 심지층 처분 시설을 가정하고 안전성평 가를 수행하기 위해 필요한 지하수 유동 자료를 작성하기 위한 지하수 유동 모의가 수행 되었다. 연구지역 의 전반적인 지하수 유동 특성을 고려하기 위해, 광역 규모의 지하수 유동 모의를 먼저 실시하여 국지 규 모 지하수 유동 모의에서 이용될 경계 조건을 구하고, 현장에서 확인된 단열 자료를 반영하여 국지 규모 에서의 지하수 유동계가 모의되었다. 같은 방식으로 국지 규모에서 지하수 유동에 관한 경계 조건을 뽑아 내어 KURT 부지 규모의 지하수 유동 모의에 이용하였다. 국지 규모의 지하수 유동 모의 결과로 얻어진 지하수위 분포를 통해 입자 추적(particle tracking) 모의를 수행하여 가상의 처분 부지 위치에서 지표로 흐르는 지하수의 유동 경로를 확인하고, 경로의 길이와 지하수의 시간당 유동량(discharge rate)을 구하

1) Corresponding Author. E-mail : nyko@kaeri.re.kr 
였다. 본 연구에서 이용된 일련의 지하수 유동 모의 및 입자 추적 모의 방법은 향후 심지층 처분 시설의 안전성 평가에 필요한 자료를 작성하는데 유용하게 쓰일 것으로 기대된다.

중심단어 : 지하수 유동 모델링, 수리지질 모델, 입자 추적 모의, 지하수 유동 경로

\section{I. 서 론}

전 세계적으로 원자력 에너지의 이용 과정에서 발생하는 고준위 방사성폐기물을 처분하기 위해 여러 가지 방안이 모 색되고 있다. 현재 우리나라에서는 심지층 처분 방식을 중심 으로 처분 연구가 진행되고 있는데, 처분 시설이 건설될 것으 로 예상되는 심부 지하 환경을 파악하는 것을 포함한 여러 분 야의 연구가 이루어지고 있다[1,2]. 특히, 처분 시설이 들어설 것으로 예상되는 결정질 암반과 같은 특정한 심부 지하 환경 을 조사하고 지질 및 수리지질학적 환경을 특성화하기 위한 연구들이 지금까지 수행되고, 그 의의가 평가되고 있다.

처분 시설이 위치할 지하 심부의 지질, 지질역학, 수리지 질, 지구화학적 환경에 대한 특성화 작업을 보다 과학적으로 수행할 수 있게 하기 위해, 지하 환경 연구 시설인 KURT(KAERI Underground Research Tunnel)가 한국원자 력연구원 부지 내에 마련되었고, 심지층 처분 연구를 위한 여러 가지 활동이 이루어지고 있다[3-6]. 2007년 KURT가 건 설 완료된 이후로 KURT 주변의 지질 및 수리지질 환경에 대 한 자료가 KURT 주변 지역의 지표 및 시추공 조사와 KURT 내부에서 이루어지는 여러 가지 실험을 통해 수집되고 있다.

한국원자력연구원은 처분 시설의 안전성을 확보하는데 이 용될 수 있는 연구들과 지금까지 축적해온 자료를 이용하여 KURT 환경에 가상의 처분 시설이 위치하고 있다고 가정하 고, 해당 시설에 대한 폐쇄 후 안전성을 평가하여 분석하였 다. 그리고 그 내용은 해외의 국제적인 전문가 집단에 의해 검토되었다[7]. 전문가의 검토를 통해 그동안 이루어져왔던 연구의 타당성을 검증받고, 아직 부족하거나 앞으로 이루어 져야 할 연구에 대한 의견 교환이 이루어졌다.

KURT 자료를 이용한 가상의 처분 시설에 대한 안전성 평 가를 수행하기 위해서는 KURT 부지 주변에 대한 지하수 유 동 자료가 필요하다. 본 논문에서는 지하수 유동 자료를 얻기 위해 이루어진 지하수 유동과 유동 경로 모의 결과에 관해 서 술하려고 한다. KURT 부근의 지형, 지질 등의 자료를 이용하 여 수리지질 모델이 작성되고, 그 구성 요소에 대한 수리지질 학적 특성이 측정, 분석되었다. 광역 및 국지 규모의 지하수 유동 모의가 순차적으로 이루어지고, 가상으로 지정된 처분
시설의 위치에서 지표까지 지하수가 유동하는 경로를 계산하 였다. 마지막으로, 전체 모의 과정과 지하수 유동 시간에 대 한 토의가 이루어졌다. 단, 본 논문은 지하수 유동 모의 부분 에 중점을 두어 작성되었으며, 수리지질 모델을 작성하는데 필요한 지질모델과 그것을 구성하는데 요구되는 지형, 지질 자료, KURT 부지에 가정된 가상의 심지층 처분 시설의 위치 등에 관한 내용은 본 논문이 실리는 특별호의 다른 해당 논문 을 참고하길 바란다.

\section{KURT 주변 수리지질 모델 구성}

\section{가. 수리지질 개념모델의 작성}

수리지질 모델은 지질 모델을 이루는 각각의 요소에서 지하 수가 어떠한 유동 양상을 보이는가에 따라, 즉 유동량의 크기 차이에 따라 각 요소를 투수성의 차이로 나누어 다시 구성한 모 델이라고 할 수 있다. 이로 인해 수리지질 모델은 일반적으로는 지질 모델을 기초로 구성되지만, 지질 모델의 각 요소에서 나타 날 수 있는 수리지질학적 특성의 차이로 인해 지질 모델과 수리 지질 모델이 바로 대응하기보다는 일부 요소가 삭제되거나 첨 가되기도 한다. 예를 들면, 일반적으로 기반암은 수리전도도가 매우 낮게 특정되어 투수성이 매우 적은 수리지질 요소가 되지 만, 투수성이 매우 좋은 다수의 단열이 기반암에 존재하여 해당 지역의 지하수 유동계에 매우 큰 영향을 끼친다면, 이를 투수성 이 양호한 수리지질 요소에 첨가시킬 수도 있다.

지질 조사를 통해 작성된 지질 모델은 상부 토양층과 풍화 대, 저경사 단열대(low angle fracture), 단열대, 기반암의 네 개의 요소로 구성되었다[2,5]. 지질 모델을 이용하여 구성된 수리지질 개념모델은 상부의 토양층과 풍화대로 이루어진 수 리토양대(Hydraulic Soil Domain, HSD), 기반암으로 이루어 진 수리암반대(Hydraulic Rock Domain, HRD), 단열대로 이 루어진 수리투수대(Hydraulic Conductor Domain, HCD), 저 경사 단열대로 이루어진 저경사 단열대(Low Angle Fractured Domain, LAFD)로 구분하였다[2].

\section{나. 수리지질 모델 구성 요소의 수리특성 분석}

수리지질 모델의 각 요소를 이루는 토양층과 풍화대, 기반 
암, 단열대의 수리전도도를 포함한 수리특성은 시추공에서 수행된 구간별 정압주입시험(constant head injection test)을 통해 측정되었다. 구간별 정압주입시험은 시추공을 일정한 간격으로 나누고 각 구간의 상, 하부를 팩커(packer)를 이용 하여 폐쇄시킨 후에, 해당 구간에 일정한 수압을 가하여 주입 되는 유량을 통해 수리전도도를 측정하게 된다[8]. 연구 지역 의 일부 시추공에서 정압주입시험을 통해 측정된 수리전도도 가 Fig. 1 에 도시되었다.

수리지질 모델의 각각의 구성 요소에 대한 수리전도도는 구간별로 측정된 값을 통계적으로 분석하여 결정하였다. 상 부 토양층과 풍화대가 포함된 수리토양대의 경우, 시추공의 착정 상태에 따라 측정이 불가능한 상황도 있어 일부 시추공 에서만 측정된 자료를 이용하여 산출된 수리전도도인 $1.50 \times$ $10^{-7} \mathrm{~m} / \mathrm{s}$ 의 값을 이용하였다.

그 외의 수리지질 모델의 요소별 수리전도도 분포는 Fig. 2 에 나타내었다. 분포를 분석해보면, 저경사 단열대의 수리전 도도 분포는 수리암반대에 비해서는 매우 크고, 단열대로 이 루어진 수리투수대와도 상이한 분포를 보이고 있어 두 수리 지질 요소와 구별해야 함을 알 수 있다.

수리투수대에 존재하는 단열대의 수리전도도 분포는 대수 정규분포(log-normal distribution)를 따르지 않고, $10^{-11}$ $10^{-5} \mathrm{~m} / \mathrm{s}$ 의 범위에 마치 두 개의 최빈값을 가진 분포(bimodal distribution)의 형태를 보이고 있어 단열대 전체를 대 표할 수 있는 수치를 설정하기에 어려움이 있다. 이로 인해 지 질 모델의 분류 체계인 단열대의 크기와 방향성을 기준으로 수리전도도 분포를 다시 분석하였다(Fig. 3).

수리투수대를 이루는 단열대의 수리전도도를 다시 분석한

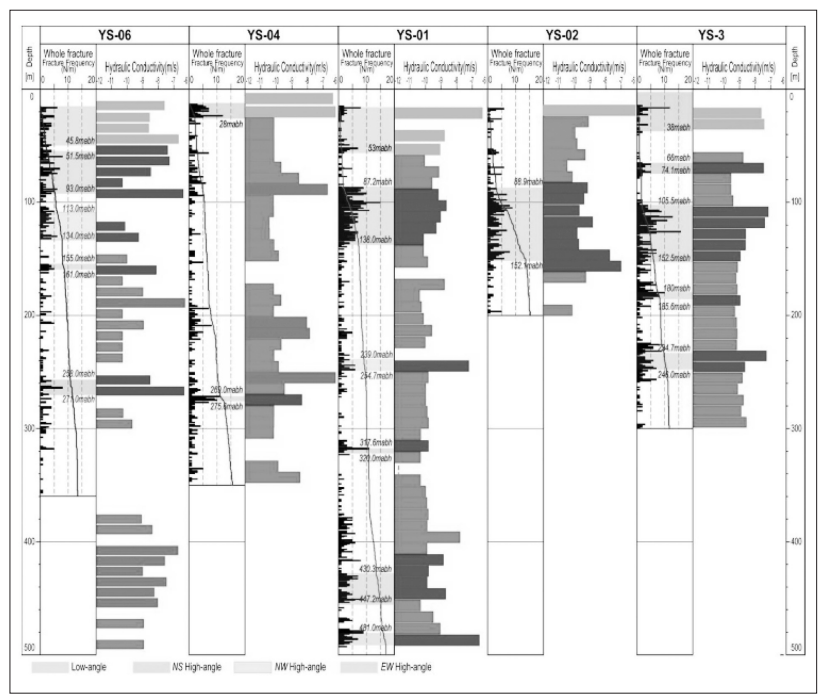

Fig. 1. Hydraulic conductivity from the constant head injection tests $[2,9]$.
결과를 보면, 단열대의 크기와 방향성에 따른 수리전도도 분 포에서 통계적인 대표 특성값을 확인하기가 쉽지 않다(Fig. 3). 따라서 각 단열대의 위치와 연결성, 크기 등의 복합적인 요소에 의해 단열대의 수리전도도가 결정되는 것으로 판단되 었다. 이로 인해 전체 단열대에 동일한 대푯값이 아닌, 단열대 별로 상이한 수리전도도가 적용되어야 한다고 설정하였고, 지하수 유동 모의 영역에 입력된 단열대의 수리전도도도 각 단열대에 따라 다르게 입력되었다. 또한, 수리투수대의 이런 특성을 이용하여 저경사 단열대도 수리투수대에 포함시켜 지 하수 유동 모의에 이용하였다. 각각의 지하수 유동 모의 영역

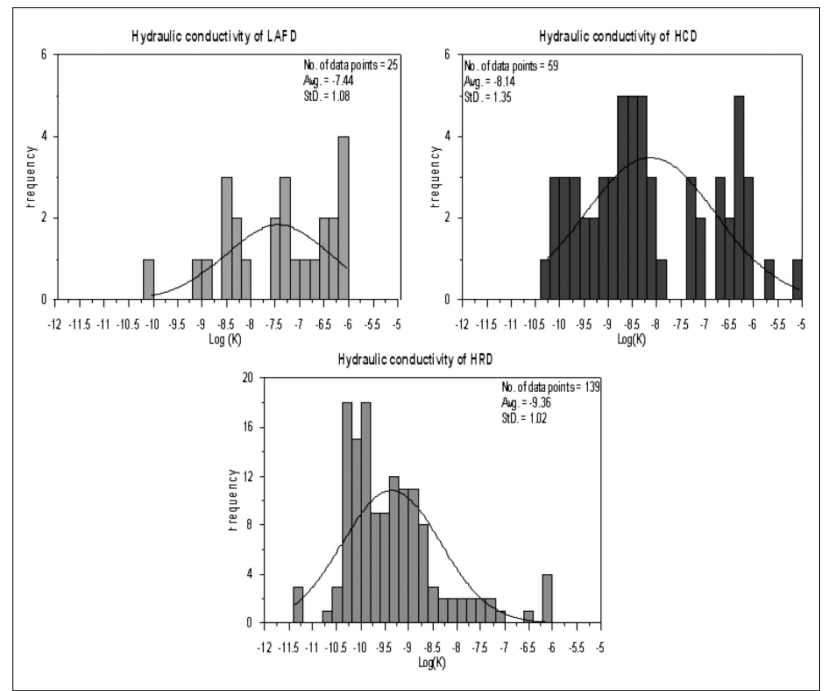

Fig. 2. Distributions of the hydraulic conductivity for LAFD, HCD, and HRD [2].

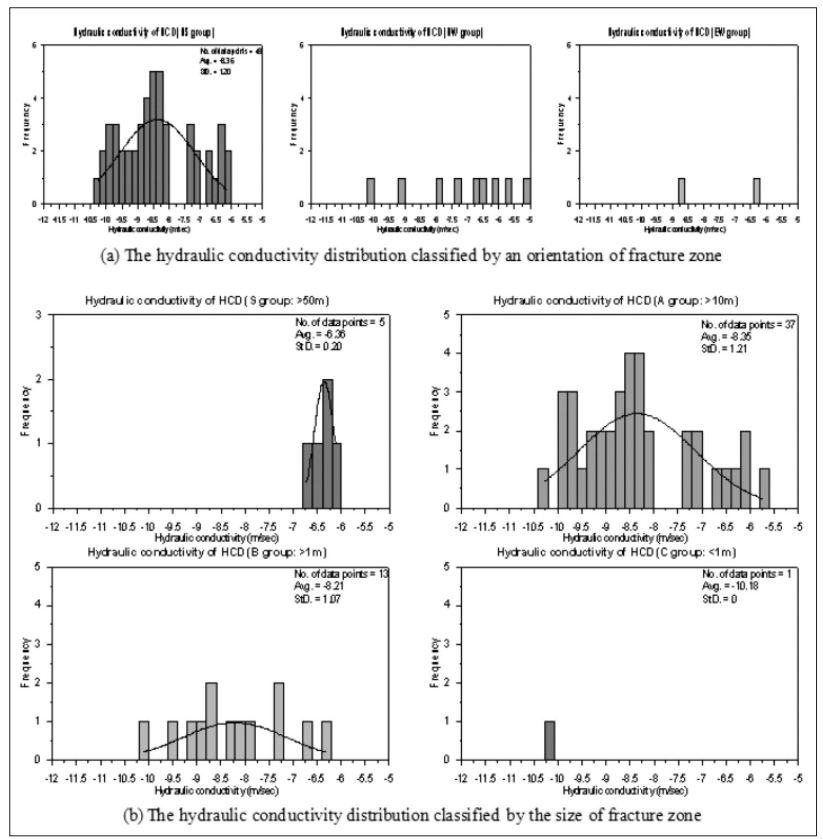

Fig. 3. Distribution of hydraulic conductivity of HCDs [2]. 
에 입력된 수리전도도는 Table 1 과 같다.

\section{KURT 주변 지하수 유동 모의 결과}

\section{가. 광역 규모 지하수 유동 모의}

KURT 주변의 광역 지하수 유동 모의 결과를 이용하여 국 지 규모 모의에서 이용할 경계 조건을 도출하기 위해, 국지 규모를 포함하는 광역 규모의 지하수 유동계를 모의하였다. 지하수 유동이 일어나는 영역을 유한요소법을 이용해 이산 화하여 지하수 유동 양상을 수치적으로 계산하였다. 지하수 유동 모의 영역은 포화대(saturated zone)만으로 한정하였 고, 정류 상태(steady state)의 지하수 유동계만을 모의하였 다. 광역 규모의 지하수 모델링 영역은 KURT를 중심으로 북쪽과 북서쪽은 금강과 그 지류를, 동쪽과 남쪽, 남서쪽은 갑천과 그 지류들이 둘러싸고 있는데, 이들 하천은 지하수 위 유동 경계로 설정되었다(Fig. 4).

모의된 광역 규모의 지하수 수두 분포를 보면, 대부분의 지하수는 지형의 등고선을 따라 산지 지역에서 하천으로 흘 러가는 경향을 보인다[6,9](Fig. 4). 모델링 영역에서 재충진 구역(recharge area)은 상대적으로 고지대인 비학산, 금병 산, 우성이산 부근으로 나타났다. 지표수인 하천의 분포와 고지대를 잇는 능선의 분포를 따라 여러 단위의 지하수 유 동 유역이 확인된다. 특히, 고지대의 능선을 중심으로 지하 수 유동이 분리되어 나타나는 지하수계의 분수령이 확연히 구분되어 나타났다. 광역 지하수 유동 모의 결과에서 나타 나는 이러한 지하수계의 분수령이 있는 산지의 능선 주위를 국지 규모의 지하수 유동 모델에서는 불투수경계(no-flow boundary)로 설정하여 지하수 유동 모의에 이용하였다.

\section{나. 국지 규모 지하수 유동 모의}

국지 규모 지하수 유동 모의는 KURT 주변의 국지 규모

Table 1. Hydraulic conductivity of the hydrogeological units [2].

\begin{tabular}{|c|c|c|c|}
\hline $\begin{array}{c}\text { Components of } \\
\text { hydrogeological model }\end{array}$ & \multicolumn{2}{|c|}{ Components of geological model } & $\begin{array}{c}\text { Hydraulic } \\
\text { conductivity }(\mathrm{m} / \mathrm{s})\end{array}$ \\
\hline HSD & \multicolumn{2}{|c|}{ Soil layer and weathered zone } & $1.50 \times 10^{-7}$ \\
\hline \multirow{11}{*}{$\mathrm{HCD}$} & \multicolumn{2}{|c|}{ Low-angle fracture zones } & $1.05 \times 10^{-7}$ \\
\hline & \multirow{10}{*}{ Fracture zone } & FZ2S-1 & $3.17 \times 10^{-7}$ \\
\hline & & FZ2S-2 & $4.36 \times 10^{-7 *}$ \\
\hline & & FZ2A-1 & $2.57 \times 10^{-9}$ \\
\hline & & FZ2A-2 & $1.69 \times 10^{-9}$ \\
\hline & & FZ2A-3 & $5.49 \times 10^{-9}$ \\
\hline & & FZ2A-4 & $6.31 \times 10^{-7}$ \\
\hline & & FZ2A-5 & $4.57 \times 10^{-7}$ \\
\hline & & FZ2A-6 & $1.32 \times 10^{-6}$ \\
\hline & & FZ2A-7 & $8.78 \times 10^{-6}$ \\
\hline & & FZ2B-1 & $7.95 \times 10^{-6}$ \\
\hline HRD & \multicolumn{2}{|c|}{ Host rock } & $4.30 \times 10^{-10}$ \\
\hline
\end{tabular}

지하수 유동 시스템을 이해하고 KURT 부근의 지하수 유동 계 및 지하수내 용질의 이동 경로를 모의하기 위해 수행하 였다. 이 때 모의 영역의 상부는 지질, 수리지질모델을 바탕 으로 수리토양대로 가정하였으며, 수리토양대와 수리암반 대, 수리투수대의 각 단열대의 수리지질특성은 각각에 대하 여 측정된 자료에서 도출한 수리지질특성을 그대로 부여하 였다.

모의 결과에 따르면 지하수는 모의 영역 북쪽 경계의 고 지대와 KURT 남쪽에 있는 적오산에서 함양되어 주변 지표 수 분포를 따라 방사형으로 퍼져간다(Fig. 4). 그리고 저지 대에 존재하는 하천의 영향으로 인해 하천 부근에서 지하수 유속이 비교적 빠르며, 상부 토양층과 풍화대의 높은 수리 전도도로 인해 심부보다는 지표 부근에서 보다 많은 지하수 유동이 발생한다.

KURT 주변에 발달한 단열대(Fig. 5)를 고려하여 삼차원 적 지하수 유동을 더욱 자세히 분석해 보면, KURT 부근의 상부 지하수 역시 지형의 영향을 많이 받는 것을 알 수 있다 (Fig. 6a). 모의 영역의 경계가 되는 북쪽의 고지대에서 남쪽 의 하천 부분으로 지하수의 주된 유동이 나타난다. 지표 부

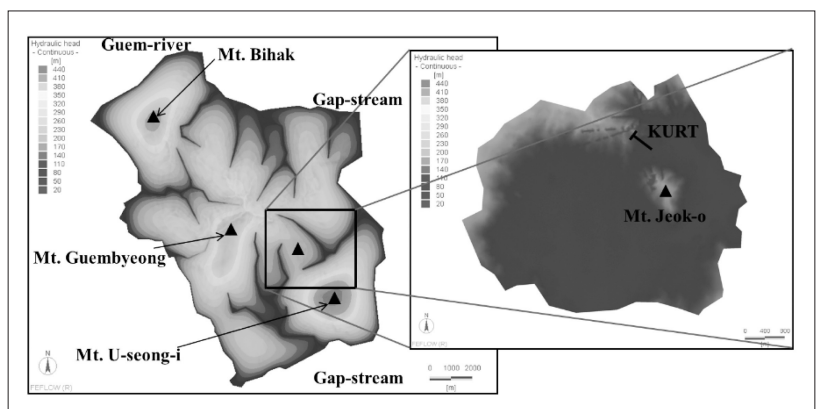

Fig. 4. Hydraulic head distributions of the regional and local scales.

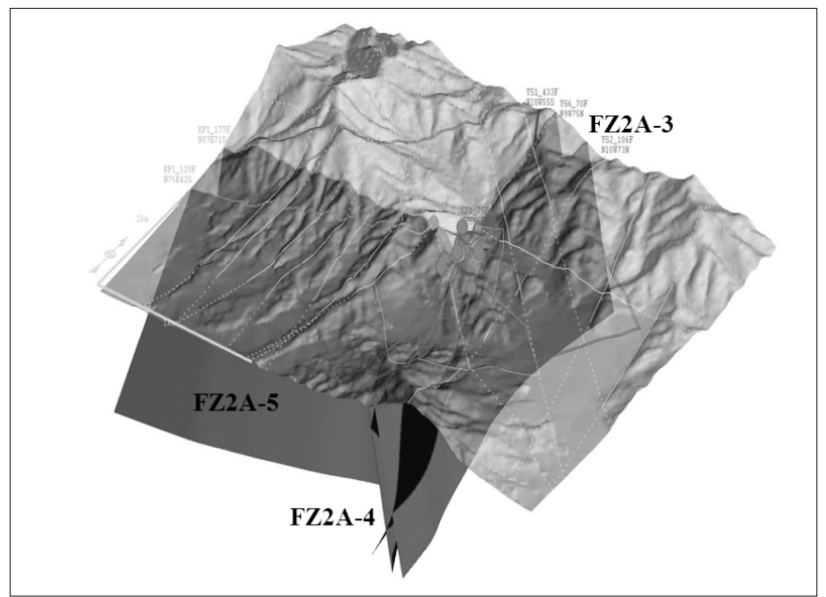

Fig. 5. Major fractures represented as HCDs in the KURT site. The characters included in the map mean the names of some fracture zones (modified from [2]). 
근에서의 이런 흐름은 가상의 처분 심도로 설정된 심도인 지하 $200 \mathrm{~m}, 500 \mathrm{~m}$ 에서도 유사하게 나타나지만, KURT 내 부와 그 부근에서의 지하수 관정에서의 공내 검층과 지구물 리 탐사 등에 의해 확인된 단열대에 의해 지하수 유동계가 교란되는 양상도 보여준다(Fig. $6 \mathrm{~b}$ and $6 \mathrm{c}$ ). 특히, 남북 방 향으로 발달된 단열대(FZ2A-2와 FZ2A-4)는 주로 남북 방향 으로 흐르는 지하수의 흐름을 교란시켜 동서방향의 흐름이 국지적으로 우세하게 나타나게 만든다. 심도가 깊어질수록

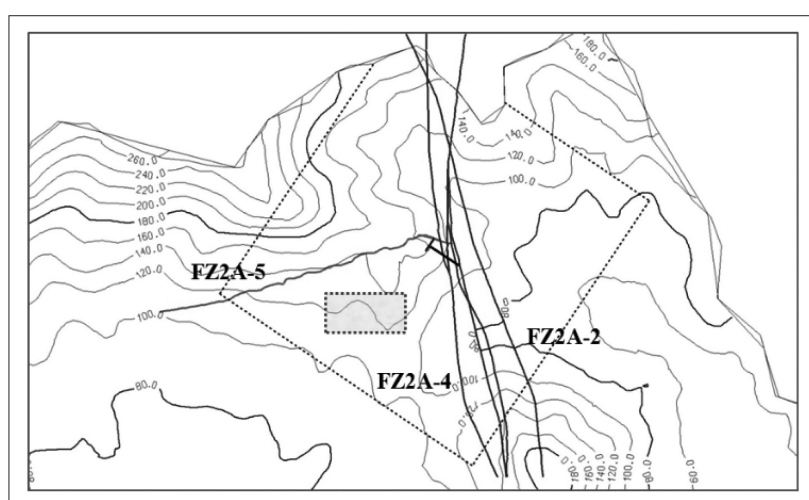

(a)

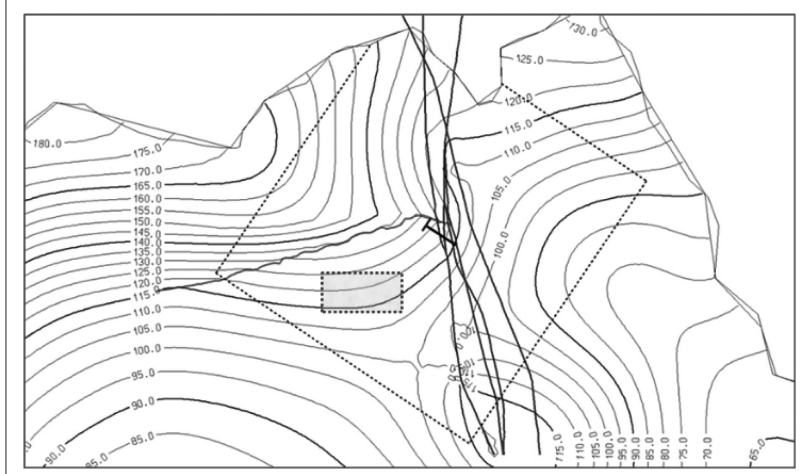

(b)

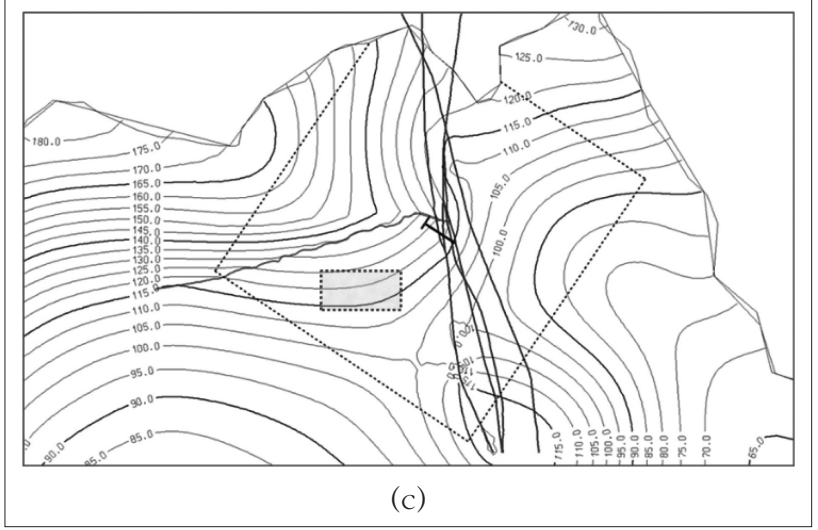

Fig. 6. Hydraulic head distributions (a) at the water table, (b) at the depth of $-200 \mathrm{~m}$, and $(\mathrm{c})$ at the depth of $-500 \mathrm{~m}$. The characters included in the map mean the names of some fracture zones, and the small rectangle filled with red color represents the hypothetical repository.
적오산 부근에서 함양되는 지하수의 영향은 감소하게 된다.

\section{IV. 처분 시설 후보 위치에서의 입자 추적 모의 결과}

실제로 심지층 처분 시설의 위치를 정하기 위해서는 광역 적인 지각운동, 지하수의 화학적 특성, 지하수의 유속과 배 출지역까지의 유동거리, 지질구조적 특성 등을 종합하여 결 정해야 한다[9]. 다만, 본 연구에서는 가상의 처분 시설의 안 전성 평가를 위해 필요한 자료인 지하수 유동 경로를 작성 하기 위한 지하수 유동 모의에 중점을 두고 있으므로, 처분 시설의 위치를 결정하는 방안에 관해서는 본 논문이 실린 특별호의 다른 논문을 참고하기 바란다.

\section{가. 지하수 유동 경로 계산}

제시된 후보 구역 중에서 하나를 선정하여 가상의 처분 시설의 위치로 선정하고, 처분 시설에서 지표로 흐르는 지 하수의 유동 경로를 입자 추적(particle tracking) 기법을 이 용하여 계산하였다[6,9](Fig. 7). 처분장은 지하 $500 \mathrm{~m}$ 지점 에 위치하는 것으로 가정하고, 그 크기는 $400 \mathrm{~m} \times 200 \mathrm{~m}$ 로 하였다. 입자 추적 모의에 이용될 지하수의 수두 분포는 국 지 규모의 지하수 유동 모의 결과를 이용하였다. 국지 규모 의 지하수 유동 모의에는 KURT 주변에 존재하는 단열대도 입력되었기 때문에 단열대에 의해 교란되는 지하수의 유동 및 수두 분포에 의해 지하수의 유동 경로가 단열대와 같이 투수성이 크고 지하수 유동량이 많은 수리지질 구조에 어떠 한 영향을 받게 되는가를 분석하는데 이용되었다.

입자 추적 모의 결과를 보면 일부는 주변의 단열 암반에 비해 지하수 유동량이 매우 큰 단열대(FZ2A-4)를 통해 지표 방향으로 유동하고, 나머지는 단열 암반 매질만을 거쳐 지 표에 이르는 것으로 나타났다(Fig. 7). 지하수 유동 경로는

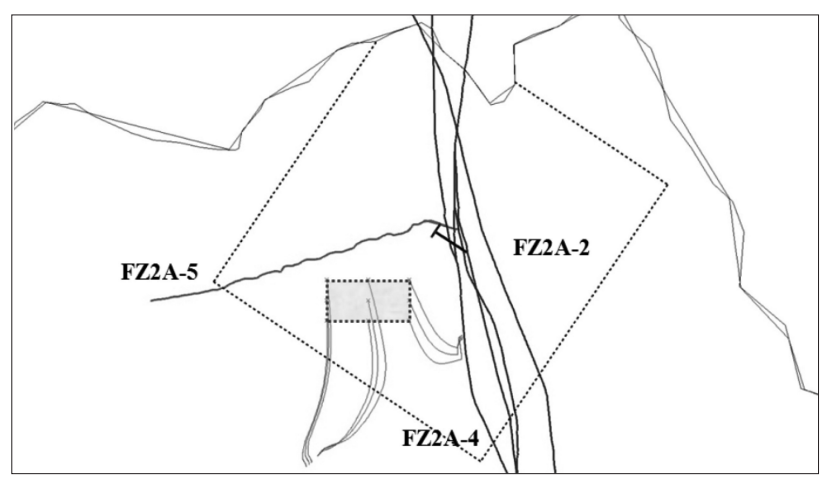

Fig. 7. Results of particle tracking simulations for pathways of groundwater from the hypothetical repository represented as the small rectangle filled with red color. The characters included in the map mean the names of some fracture zones. 
지형에 크게 영향을 받는 지하수두 분포에 따라 주로 남쪽 으로 나타나지만, 모의 영역의 남북 방향으로 발달한 단열 대(FZ2A-4)에 가까워질수록 동쪽 방향으로 치우치는 현상 을 보인다. 단열대를 따라 지표로 이어지는 경로가 단열대 와 만나는 심도는 약 $-350 \sim 250 \mathrm{~m}$ 정도이다. 일단 단열대 와 만난 유동 경로는 단열대를 따라 지표 방향으로 상승하 는 경향을 보인다(Fig. 8).

단열 암반만을 거쳐 지표의 하천으로 흘러나오는 지하수 의 유동 거리는 $975 \sim 1210 \mathrm{~m}$ 로 나타났고, 그때의 지하수 들의 암반내 시간당 유동량(discharge rate)은 $5.6 \sim 6.0 \times$ $10^{-4} \mathrm{~m} / \mathrm{yr}$ 로 나타났다. 반면에, 단열대를 따라 지표로 나오 는 지하수는 단열 암반과 단열대를 거쳐 흐르는 거리는 830 $898 \mathrm{~m}$ 로 나타났으며, 암반 영역에서는 $419 \sim 446 \mathrm{~m}$, 단 열대에서는 $393 \sim 452 \mathrm{~m}$ 의 유동 경로를 거치는 것으로 계 산되었다. 지하수의 시간당 유동량은 단열 암반에서는 5.2 $\sim 5.6 \times 10^{-4} \mathrm{~m} / \mathrm{yr}$, 단열대에서는 $7.5 \sim 8.1 \times 10^{-1} \mathrm{~m} / \mathrm{yr}$ 로 계산되었다.

\section{V. 토의 및 결론}

KURT의 지질 및 기타 환경을 이용하여 가상의 심지층 처 분 시설에 대한 안전성 평가를 수행하는데 필요한 지하수 유동 자료를 작성하기 위해 지하수 유동계의 모의가 수행되 었다. 모의에 이용된 수리지질 모델은 KURT 부근에서 이루 어진 지질 조사를 통해 작성된 지질 모델을 기초로 구성되 었다. 수리지질 모델을 이용하여 광역 모델에 대한 모의를 수행하고, 그 결과를 이용하여 국지 모델의 경계 조건을 설

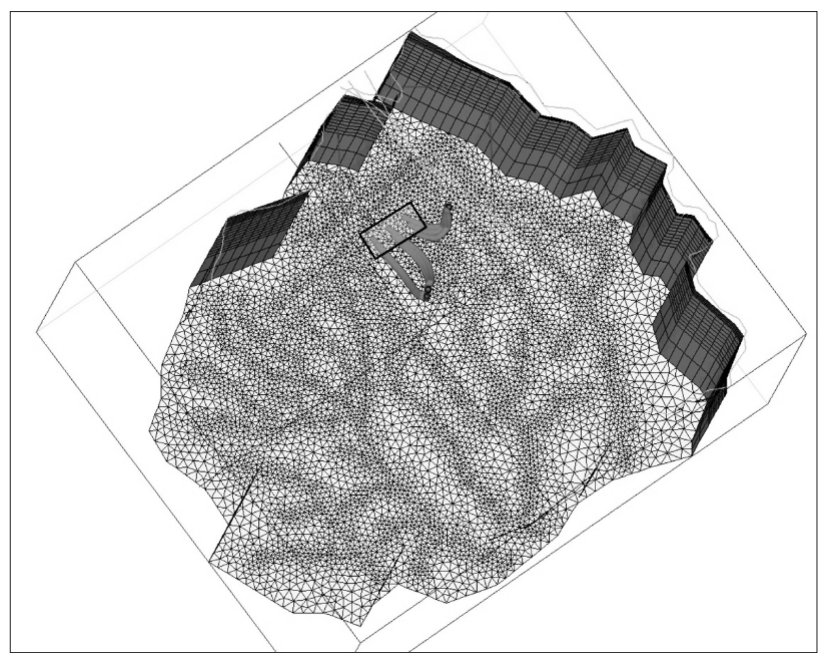

Fig. 8. 3-D view of pathways of groundwater from the hypothetical repository. The rectangle area surrounded by black lines represents the hypothetical repository.
정하였다. 국지 모델에서는 KURT에서 관측된 단열대를 반 영하여 지하수 유동계를 모의하였다. 국지적인 지하수 유동 모의 결과는 가상적으로 선정된 심지층 처분 시설의 위치에 서 지표로 흐르는 지하수의 유동 경로를 계산하는데 이용되 었다.

가상의 처분 시설 위치에서 지표까지 흐르는 지하수의 경 로를 계산하기 위해 수리지질 개념모델의 구성부터 입자 추 적 모의까지의 과정이 순차적으로 이용되었다. 일련의 계산 과정에서 KURT 건설 이후 지금까지 축적되어 왔던 자료들 이 이용되고, 그 이용 방법에 대한 연구와 검토가 이루어지 면서 보다 시스템적인 분석이 가능하게 되었다. 다만, 아직 은 단열대와 기반암의 자료에 대한 불확실성이 상대적으로 큰 편이고 수리지질 자료도 충분하지 않기 때문에 모의 결 과에 상당한 불확실성이 존재한다. 이를 해소하기 위해 앞 으로도 많은 자료가 장기간에 걸쳐 획득되어야하며, 불확실 성을 줄일 수 있는 분석 방법의 연구도 이루어져야 할 것이 다.

\section{감사의 글}

이 논문은 교육과학기술부 원자력연구개발사업의 지원을 받았음을 밝히며 이에 감사드립니다.

\section{References}

[1] Korea Atomic Energy Research Institute, HLW long-term management technology development Assessment of deep geological environmental condition, KAERI Research Report, 503 p., KAERI/RR-2783/2006 (2007).

[2] Korea Atomic Energy Research Institute, HLW long-term management technology development Assessment of deep geological environmental condition for HLW disposal in Korea, KAERI Research Report, 435 p., KAERI/RR-3109/2009 (2010).

[3] W.-J. Cho, S. Kwon, J.-H. Park and J.-W. Choi, ” KAERI Underground Research Tunnel (KURT)," Journal of the Korean Radioactive Waste Society, 5(3), pp. 239-255 (2007).

[4] K.W. Park, Y.K. Koh, K.S. Kim and J.W. Choi," Construction of the Geological Model around KURT 
area based on the surface investigations," Journal of the Korean Radioactive Waste Society, 7(4), pp. 191-205 (2009).

[5] K.W. Park, K.S. Kim, Y.K. Koh and J.W. Choi, ” Study on the Geological Structure around KURT Using a Deep Borehole Investigation," Journal of the Korean Radioactive Waste Society, 8(4), pp. 279-291 (2010).

[6] K.W. Park, K.S. Kim, Y.K. Koh and J.W. Choi, " Synthetic Study on the Geological and Hydrogeological Model around KURT," Journal of the Korean Radioactive Waste Society, 9(1), pp. 1321 (2011).

[7] Korea Atomic Energy Research Institute, Geological disposal of pyroprocessed waste from PWR spent nuclear fuel in Korea, KAERI Technical Report, 192 p., KAERI/TR-4525/2011 (2011).

[8] V. Batu, Aquifer hydraulics, pp. 692-703, John Wiley \& Sons, Inc., New York (1998).

[9] K.S. Kim, K.W. Park, G.Y. Kim and H.J. Choi, Development of Advanced Korean Reference HLW Disposal System - Site Characteristics, KAERI Technical Report, 64 p., KAERI/TR-4265/2011 (2011). 